\title{
Competing risk of death and end-stage renal disease in incident chronic kidney disease (stages 3 to 5): the EPIRAN community-based study
}

Carole Ayav ${ }^{1,2}$, Jean-Baptiste Beuscart ${ }^{3,4}$, Serge Briançon ${ }^{1,2,5}$, Alain Duhamel ${ }^{4}$, Luc Frimat ${ }^{5,6}$ and Michèle Kessler ${ }^{6^{*}}$

\begin{abstract}
Background: Although chronic kidney disease (CKD) affects a growing number of people, epidemiologic data on incident CKD in the general population are scarce. Screening strategies to increase early CKD detection have been developed.

Methods: From a community-based sample of 4,409 individuals residing in a well-defined geographical area, we determined the number of patients having a first serum creatinine value $\geq 1.7 \mathrm{mg} / \mathrm{dL}$ and present for at least 3 months that allowed us to calculate an annual incidence rate of CKD (stages 3 to 5). CKD (stages 3 to 5) was defined by estimated glomerular filtration rate (eGFR) $<60 \mathrm{~mL} / \mathrm{min} / 1.73 \mathrm{~m}^{2}$. We also described the primary care, outcomes and risk factors associated with outcomes using competing risks analyses for these CKD patients.

Results: A total of 631 incident CKD patients (stages 3 to 5) were followed-up until the occurrence of death and dialysis initiation for more than 3 years. The annual incidence rate of CKD (stages 3 to 5) was estimated at 977.7 per million inhabitants. Analyses were performed on 514 patients with available medical data. During the study, 155 patients (30.2\%) were referred to a nephrologist, 193 (37.5\%) died and 58 (11.3\%) reached end-stage renal disease and initiated dialysis. A total of 139 patients (27.6\%) had a fast decline of their renal function, $92(18.3 \%)$ a moderate decline and the 272 remaining patients had a physiological decline (21.1\%) or a small improvement of their renal function (33.0 \%). Predictors of death found in both Cox and Fine-Gray multivariable regression models included age at diagnosis, anemia, active neoplasia and chronic heart failure, but not a low glomerular filtration rate (GFR). Age at diagnosis, anemia and a low GFR were independently associated with dialysis initiation in Cox model, but anemia was not found to be a risk factor for dialysis initiation in Fine-Gray model.

Conclusions: This large cohort study provided useful epidemiological data on incident CKD (stages 3 to 5) and stressed the need to improve the hands-on implementation of clinical practice guidelines for the evaluation and the management of CKD in primary care.
\end{abstract}

Keywords: Chronic kidney disease, Competing-risk analysis, Epidemiological study, Incidence, Outcomes, Risk factors

\footnotetext{
* Correspondence: m.kessler@chru-nancy.fr

${ }^{6}$ Department of Nephrology, University Hospital, Vandœuvre-les-Nancy,

France

Full list of author information is available at the end of the article
} 


\section{Background}

Chronic kidney disease (CKD) is a common condition and the increased incidence of end-stage renal disease (ESRD) is a growing public health challenge worldwide [1-6]. Less than $2 \%$ of CKD patients in all stages except stage 4 progress to ESRD and undergo renal replacement therapy (RRT) [7]. CKD is associated with a markedly increased risk of cardiovascular morbidity and mortality and it is clear that the majority of CKD patients, especially those aged 75 and over, dies before reaching ESRD largely due to worsening heart disease [7-12].

The early identification of patients at increased risk for CKD or in the early stages is therefore critical and could facilitate timely therapeutic interventions to slow both progression of CKD to ESRD and cardiovascular diseases with benefits on both kidney and patient survival $[13,14]$. Thus screening strategies to increase early recognition of individuals at risk were developed implementing surveillance of elevated plasma creatinine, microalbuminuria, and more recently routine reporting of estimated glomerular filtration rate (eGFR) in a high-risk target population [3, 15-22]. Family general practitioners (GPs) are responsible for CKD screening and timely referral to nephrologist. This creates opportunity for coordinated and optimal management of CKD to reduce morbidity and mortality [23].

Epidemiological data on incident CKD in the general population are the only ones permitting non-biased prognostic studies to be carried out, but they are scarce [5]. A recent literature review highlighted substantial heterogeneity between prevalence studies related to a wide range of study designs, criteria used for the selection of patients, and methods for measuring renal function [2]. Among the 43 selected studies, 6 high-quality studies allowed an estimate of the prevalence in a range of 1.7 to $8.1 \%$.

The objectives of the present community-based study was to determine the number of patients residing in a well-defined geographical area having a first serum creatinine value $\geq 1.7 \mathrm{mg} / \mathrm{dL}$ after January $1^{\text {st }}, 2004$ and still present for at least 3 months, and to describe their primary care, outcomes and risk factors associated with outcomes using competing risks analyses.

\section{Methods}

\section{Study design}

EPIRAN (EPidémiologie de l'Insuffisance Rénale chronique dans l'Agglomération Nancéienne) was a communitybased epidemiological study based on active and passive data collection. The EPIRAN study was a prospective observational cohort study. As a result, the assignment of a human participant to a particular health-related intervention was not designed in advance by a trial protocol but fell within current clinical practice.

The study was conducted in the general population from a well-defined geographical area, the Urban Community of Greater Nancy (UCGN). This area is located in Eastern France and comprises a population of 258,000 inhabitants according to the 1999 census; it has a University Hospital and 2 private clinics.

\section{Study population}

Included patients, called incident CKD patients (stages 3 to 5 ), were all adult patients ( $\geq 18$ years) residing in the given geographical area and having a first serum creatinine value $\geq 1.7 \mathrm{mg} / \mathrm{dL}$ reached after January $1^{\text {st }}, 2004$ and present for at least 3 months.

\section{Data collection}

Our study used laboratory data from routine tests. All 16 clinical laboratories gave their agreement to participate and were asked to report electronic data on patients fulfilling the inclusion criteria. As eGFR was not automatically generated by laboratories in France in 2004, its assessment could not be used as a diagnostic criterion.

In the absence of patient's objection, validation of data was conducted on 50000 dosages that had been declared in two and a half years. To avoid duplication between laboratories, double-entries were systematically checked first. Then previous creatinine levels were screened for each patient in order to identify prevalent CKD patients. When the first high creatinine measurement was not confirmed after a 3-month period we systematically searched for a creatinine level $<1.7 \mathrm{mg} / \mathrm{dL}$. At the end of this process, all patients with a creatinine level $\geq 1.7 \mathrm{mg} / \mathrm{dL}$ prior to January $1^{\text {st }}, 2004$, or a level lowered back to below $1.7 \mathrm{mg} / \mathrm{dL}$ were excluded. Only creatinine values $\geq 1.7 \mathrm{mg} / \mathrm{dL}$ were systematically reported by laboratories in the UCGN from January $1^{\text {st }}$, 2004 to June $30^{\text {th }}, 2006$.

An expert committee composed of nephrologists and epidemiologists critically reviewed and validated all exclusions and inclusions, and confirmed the persistence of kidney injury for all included patients, using a standardized process.

Each prescribing physician was contacted by a study nurse to give additional information on registration status. Each GP was asked about history of kidney disease and nephrology care. However, some GPs refused to provide any data about their patients. Consequently, 117 patients had missing data for all covariates except age, sex, and creatinine level, and were excluded in statistical analyses of secondary objectives.

Clinical and biochemical characteristics were collected. eGFR was calculated using the simplified Modification of the Diet in Renal Disease (MDRD) formula for 
patients with creatinine level $\geq 1.7 \mathrm{mg} / \mathrm{dL}$ [24]. CKD (stages 3 to 5 ) was defined solely by eGFR $<60 \mathrm{~mL} /$ minute $/ 1.73 \mathrm{~m}^{2}$. The number of included patients allowed us to calculate an annual incidence rate of CKD (stages 3 to 5).

As the study was aimed to observe the management of patients in real life, and therefore based on the strict respect of usual GP's medical practice, the only visits and assessments collected by the study nurses were those carried out and requested by GPs. GPs were therefore free to schedule visits, order additional laboratory testing, and refer their patients to nephrologists.

Patients were followed-up until the occurrence of death, dialysis initiation, move outside the study area, or the end of the study (date of point on December $31^{\text {st }}, 2009$ ).

Progression of CKD during the study period was classified as following: improvement of eGFR if the difference between the final and initial values of serum creatinine (fSC-iSC) was $\leq 0$, physiological decline if $0<\mathrm{fSC}-\mathrm{iSC} \leq 2$, moderate decline if $2<\mathrm{fSC}$ iSC $<5$ and fast decline if $\mathrm{fSC}-\mathrm{iSC} \geq 5$ [25].

Data about nephrology care, dialysis initiation and kidney transplant were collected for all included patients from all three nephrology departments located in the UCGN and from the French Renal Epidemiology and Information Network (REIN) registry [26]. To identify deaths among all included patients, the national register of deaths was interrogated at the end of the follow-up period [27].

\section{Statistical analyses}

The annual incidence rate of CKD (stages 3 to 5) in UCGN was estimated from the whole study cohort $(N=631)$. It was calculated using the general population estimates for a health service catchment area as the denominator, based on population estimates from the 1999 Census [28]. Over the first decade of 2000, this population was unchanged [28]. Incidence rates according to gender and age were also calculated. Standardized incidence rate was also calculated according to direct standardization method and using WHO European standard population as reference [29].

Statistical analyses were performed on the 514 patients who had available characteristics. Baseline characteristics were presented in terms of mean and standard deviation (STD) for continuous variables, and expressed as frequency and percentage for categorical variables.

\section{Univariable and multivariable analyses}

Death and dialysis initiation were considered as competing risks, whereas other events were censored. The crude cumulative incidence functions were estimated for death and dialysis initiation using the method of Kalbfleisch and Prentice [30, 31]. We used two different models for uni- and multivariable analyses for the survival regression models on the whole cohort: i) a Cox proportional hazard regression model on the causespecific hazards of death and of dialysis initiation, ii) a Fine-Gray regression model on the sub-distribution hazards of death and of dialysis initiation [32,33].

\section{Management of missing data}

Given a large number of missing biological data, $\mathrm{Hb}$ level was the only variable taken into account. There was $11 \%$ of missing $\mathrm{Hb}$ values. Values for covariates with missing values were obtained by multiple imputations using the MICE package as recommended for a Cox proportional hazard model analysis [34]. This was achieved with regression switching imputation using linear or logistic regression models dependingon the nature of the incomplete covariate fitted [34, 35]. This procedure was repeated five times to obtain five draws for each missing value in five distinct datasets.

Covariates were selected in the multivariable analysis using a stepwise procedure adapted to multiple imputation methodology [36]. According to Rubin's approach, the coefficients and variances obtained with the final model on each imputed dataset were averaged by taking into account the intra-variance of the model and intervariance between the imputed datasets [37].

\section{Log-linearity assumption}

The log-linear assumption of the Cox proportional hazard model was assessed using the Martingale residuals [38]. Since the log-linearity assumption was violated for age, hemoglobin $(\mathrm{Hb})$ level, and eGFR, they were transformed into categorical variables. The cut-off values were identified with graphic investigations using Martingale residuals plots, maximization of the Gray test, and on the basis of medical expertise and consensus.

\section{Sensitivity analysis}

The cut-off value for eGFR was mainly determined by its association with the risk of hemodialysis which could lead to an underestimation of the relationship between eGFR and the risk of death. A sensitivity analysis was conducted to explore the relationship between the risk of death and various transformations of eGFR: continuous, logarithmic, or every possible cut-off of the variable.

\section{Softwares}

All statistical calculations were performed on SAS $\odot \mathrm{v}$ 9.2 (SAS Institute Inc., Cary, NC, USA) using the R statistical programming language and computing environment with survival, cmprsk, and Mice packages [39].

\section{Results}

A total of 49,114 creatinine values $\geq 1.7 \mathrm{mg} / \mathrm{dL}$ were reported in the UCGN from January $1^{\text {st }}, 2004$ to June $30^{\text {th }}$, 
2006. Among the 4,409 individuals, 35 patients refused to be enrolled and 110 were excluded because of lack of a second creatinine measurement; 1,012 patients with a serum creatinine $\geq 1.7 \mathrm{mg} / \mathrm{dL}$ reported prior to January $1^{\text {st }}$ 2004 were considered as prevalent CKD patients; 2,621 patients had an acute deterioration of renal function, and creatinine level lowered back to below $1.7 \mathrm{mg} / \mathrm{dL}$ during the follow-up; finally, 631 were diagnosed incident CKD patients after validation by the expert committee (Fig. 1).

The first serum creatinine measurement with a value $\geq 1.7 \mathrm{mg} / \mathrm{dL}$ was initiated by a GP for $45.0 \%$ of the 631 cases, a non nephrologist specialist for $49.5 \%$, and a nephrologist for only $5.5 \%$. Reasons why a specialist ordered a creatinine blood test were mostly a standard medical checkup on planned admission to hospital (57.8\%), on emergency visit (15.7\%), on pre-anesthesia assessment (12.8\%) and a routine follow-up for a chronic condition (13.7\%). A period of time was needed before confirmation of diagnosis by a second creatinine determination, and was similar for GPs and non nephrologist specialists (7 \pm 4.2 and $6.4 \pm 4.3$ months, respectively).

\section{Incidence rate of CKD (stages 3 to 5)}

The annual incidence rate of CKD was estimated from the whole cohort $(N=631)$ at 977.7 per million population (pmp) [902.9-1,057.0], approximately two-fold higher in men than in women $(1,338.2[1,211.5-1,474.6]$ and 654.9 pmp [571.7-746.7], respectively). Standardized incidence according to the WHO population-type was $767.1 \mathrm{pmp}$ [764.0-770.1].

Incidence rate of CKD was very low under age 45 and increased exponentially after age 55 (mean age: 76.4 \pm 12.8 years), with a male preponderance regardless of age (Fig. 2). The sex ratio male/female (1.83) decreased progressively with age from 3.89 for patients aged $55-65$ to 1.89 for patients aged $>95$.

\section{Baseline characteristics}

As some GPs refused to participate in the study, medical data were available for only 514 patients and used for the secondary objective (Fig. 1). We compared demographic characteristics of CKD patients with and without additional medical data and the only difference concerned age: $75.95 \pm 13.05$ vs. $78.52 \pm 11.56$ years, respectively $p=0.0467$. Baseline characteristics of the 514 patients are displayed in Table 1 . The majority of patients $(73.9 \%)$ were aged $\geq 70$ years at the time of diagnosis and $65.4 \%$ were men.

About one-third of patients were diabetic and onequarter had congestive heart failure (CHF). Estimated GFR was $32 \pm 8.6 \mathrm{~mL} / \mathrm{min} / 1.73 \mathrm{~m}^{2}$. All patients were CKD diagnosed at stage $3(61.1 \%)$, stage $4(32.7 \%)$ and stage 5 (6.2 \%). At inclusion, $\mathrm{Hb}$ level was $12.1 \pm 2.1 \mathrm{~g} / \mathrm{dL}$; more than half of the patients were anemic ( $\mathrm{Hb}$ level

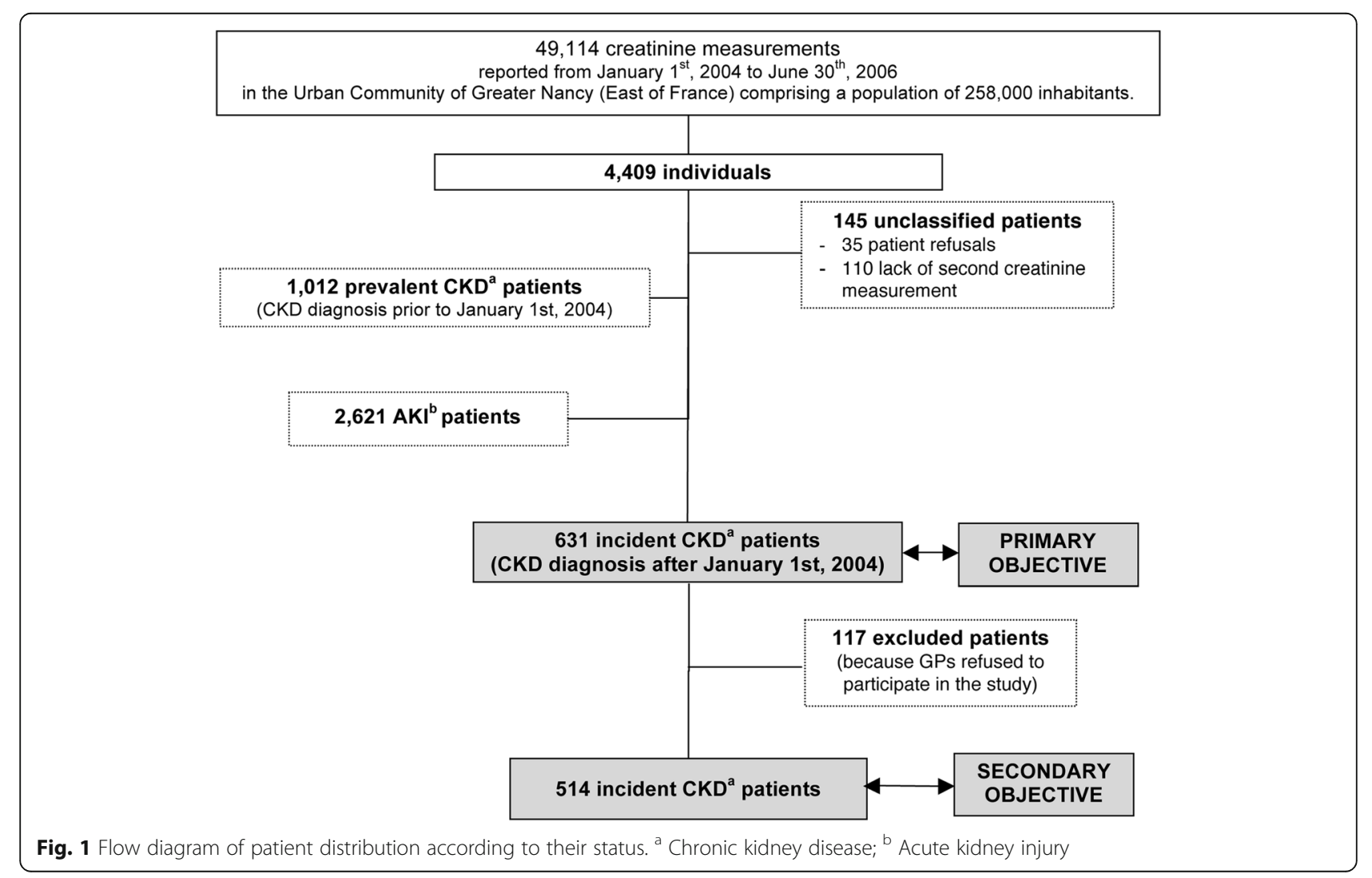




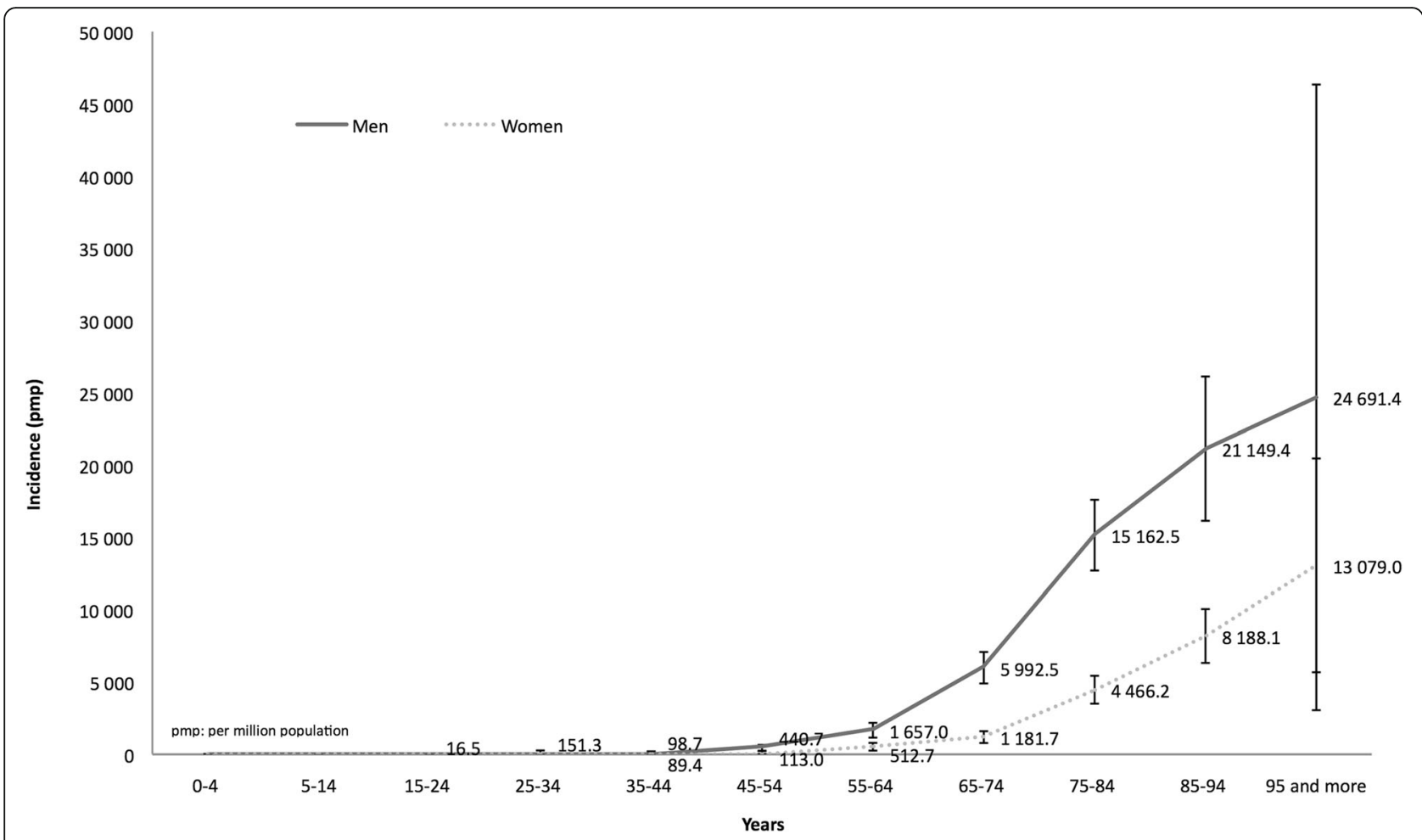

Fig. 2 Cumulative incidence of chronic kidney disease according to age at diagnosis and gender. pmp: per million population

$<12 \mathrm{~g} / \mathrm{dL}$ for women, $<13 \mathrm{~g} / \mathrm{dL}$ for men). Proteinuria was measured in only $9.7 \%$ of patients $(n=50)$. The mean value for proteinuria was $2.1 \pm 2.8 \mathrm{~g} / 24 \mathrm{~h}$ (median value: $1.2 \mathrm{~g} / 24 \mathrm{~h}$ ). At the time of the first serum creatinine value $>1.7 \mathrm{mg} / \mathrm{dL}, 15 \%$ of patients had already attended a nephrologist consultation, and $19.6 \%$ of patients had had a serum creatinine measurement as part of their follow-up care for a known nephropathy.

\section{Outcomes}

Patients were followed-up for more than three years (37.9 \pm 24.0 months). During the course of the study, a total of 155 patients $(30.2 \%)$ were referred to a nephrologist within $16.0 \pm 16.2$ months after being included, 193 (37.5 \%) died and 58 (11.3\%) reached ESRD and initiated dialysis (no preemptive kidney transplantation).

Among those who died, only $17.1 \%$ were referred to a nephrologist. The leading causes of death were: cardiovascular diseases (32.3\%), cancer (28.6\%), other or unknown (15.3\%) and infectious diseases (8.5\%). The five-year probabilities of death and dialysis initiation reached $33 \%$ and $12 \%$, respectively (Fig. 3).

A total of 139 patients $(27.6 \%)$ had a fast decline of their renal function, $92(18.3 \%)$ a moderate decline and the 272 remaining patients had a physiological decline (21.1\%) or a small improvement of their renal function (33\%) (Table 2). Fast progressors were more likely to reach ESRD or death $(p<0.0001)$.

\section{Competing risk analyses of death and dialysis initiation}

Variables associated with death using Cox univariable regression analysis were age at diagnosis, $\mathrm{Hb}$ level $<11 \mathrm{~g} / \mathrm{dL}$, active neoplasia and CHF (Table 3).

They remained independently associated with death in the Cox multivariable regression analysis (Table 4). No other variables associated with death as those identified in the Cox model were significant in the Fine-Gray model (Table 4). eGFR was not found to be a risk factor for death in the main analysis (Table 4, Fig. 4-Panel a) and in the sensitivity analysis.

Variables associated with dialysis initiation using Cox univariable regression analysis were: age at diagnosis, $\mathrm{Hb}$ level $<11 \mathrm{~g} / \mathrm{dL}$, diabetes, and eGFR $<20 \mathrm{~mL} / \mathrm{min}$ (Table 3). In the Cox multivariable regression analysis, age at diagnosis, $\mathrm{Hb}$ level $<11 \mathrm{~g} / \mathrm{dL}$, and eGFR $<20 \mathrm{~mL} /$ min remained independently associated with dialysis initiation (Table 3, Fig. 4-Panel b). No other variables associated with dialysis initiation as those identified in the Cox model were significant in the Fine-Gray univariable analysis. In the Fine-Gray multivariable model, $\mathrm{Hb}$ level $<11 \mathrm{~g} / \mathrm{dL}$ was not found to be a risk factor for dialysis initiation (Table 4).

\section{Discussion}

In the population-based EPIRAN study, we detected patients having two consecutive serum creatinine values $\geq 1.7 \mathrm{mg} / \mathrm{dL}$ over a three-month period. Each case was 
Table 1 Baseline characteristics of incident CKD patients with available data $(N=514)$

\begin{tabular}{|c|c|c|c|c|c|c|c|c|c|c|}
\hline & Missing data (\%) & $\mathrm{N}$ & $\%$ & Mean & STD & Median & Q1 & Q3 & Min & Max \\
\hline Age (year) & 0 & 514 & & 76.0 & 13.0 & 77.7 & 69.6 & 84.9 & 17.5 & 99.9 \\
\hline$<70$ & & 134 & 26.1 & & & & & & & \\
\hline $70-80$ & & 156 & 30.4 & & & & & & & \\
\hline $80-85$ & & 96 & 18.7 & & & & & & & \\
\hline$\geq 85$ & & 128 & 24.9 & & & & & & & \\
\hline Gender & 0 & & & & & & & & & \\
\hline Men & & 336 & 65.4 & & & & & & & \\
\hline Women & & 178 & 34.6 & & & & & & & \\
\hline BMI $\left(\mathrm{kg} / \mathrm{m}^{2}\right)$ & 36.9 & 324 & & 27.1 & 5.4 & 26.1 & 23.7 & 30.1 & 14.7 & 47.5 \\
\hline$\leq 20$ & & 21 & 6.5 & & & & & & & \\
\hline ]20-25] & & 97 & 29.9 & & & & & & & \\
\hline ]25-30] & & 122 & 37.7 & & & & & & & \\
\hline$>30$ & & 84 & 25.9 & & & & & & & \\
\hline $\mathrm{SBP}(\mathrm{mm} \mathrm{Hg})$ & 36.4 & 327 & & 136.8 & 22.8 & 135 & 120 & 150 & 78 & 240 \\
\hline $\mathrm{DBP}(\mathrm{mm} \mathrm{Hg})$ & 36.4 & 327 & & 73.3 & 12.6 & 70 & 66 & 80 & 38 & 120 \\
\hline Number of comorbidities & 1.3 & 507 & & 2.9 & 1.3 & 3 & 2 & 4 & 0 & 7 \\
\hline 0 & & 2 & 0.4 & & & & & & & \\
\hline 1 & & 54 & 10.7 & & & & & & & \\
\hline 2 & & 144 & 28.4 & & & & & & & \\
\hline 3 & & 155 & 30.6 & & & & & & & \\
\hline 4 & & 152 & 30.0 & & & & & & & \\
\hline Cardiovascular diseases & & 436 & 86.0 & & & & & & & \\
\hline Diabetes mellitus & & 173 & 34.1 & & & & & & & \\
\hline Ischemic cardiomyopathy & & 159 & 31.4 & & & & & & & \\
\hline Heart failure (NYHA III or IV) & & 117 & 23.1 & & & & & & & \\
\hline Hypertension & & 368 & 72.6 & & & & & & & \\
\hline Stroke & & 45 & 8.9 & & & & & & & \\
\hline Lower limb peripheral arterial disease & & 101 & 19.9 & & & & & & & \\
\hline Neoplasia & & 87 & 17.2 & & & & & & & \\
\hline Hemoglobin (g/dL) & 11.3 & 454 & & 12.1 & 2.1 & 12.1 & 10.6 & 13.5 & 5.4 & 18.4 \\
\hline Serum creatinine (mg/dL) & 0 & 514 & & 2.2 & 1.3 & 1.9 & 1.8 & 2.1 & 1.7 & 23.7 \\
\hline eGFR (mL/min/1.73 m²) & 0 & 514 & & 32.0 & 8.6 & 32.4 & 27.3 & 38.9 & 1.7 & 52.8 \\
\hline$<15$ & & 25 & 4.9 & & & & & & & \\
\hline $15-29$ & & 168 & 32.7 & & & & & & & \\
\hline $30-44$ & & 314 & 61.1 & & & & & & & \\
\hline $45-59$ & & 7 & 1.4 & & & & & & & \\
\hline
\end{tabular}

BMI body mass index, DBP diastolic blood pressure, eGFR estimated glomerular filtration rate using MDRD formula (Modification of the Diet in Renal Disease), Min minimum, Max maximum, Q1 quartile 1, Q2 quartile 2, STD standard deviation, SDB systolic blood pressure

critically reviewed by an expert committee. The annual incidence rate of CKD (stage 3 to 5 CKD defined as eGFR $<60 \mathrm{ml} / \mathrm{min} / 1.73 \mathrm{~m}^{2} /$ year) was estimated to 977.7 pmp using routine blood testing systematically reported by clinical laboratories of an urban territory with a population of 250,000. The incidence was two-fold higher in men than in women. This result is not surprising given the fact that the same cut-off was used in both genders. The identified patients were elderly with multiple comorbidities. Our results were close to that previously observed [40]. Studies conducted to define incidence for CKD are scarce, most of studies evaluate its prevalence $[3-5,40]$. Prevalence studies indicate CKD burden whereas incidence studies contribute to the 


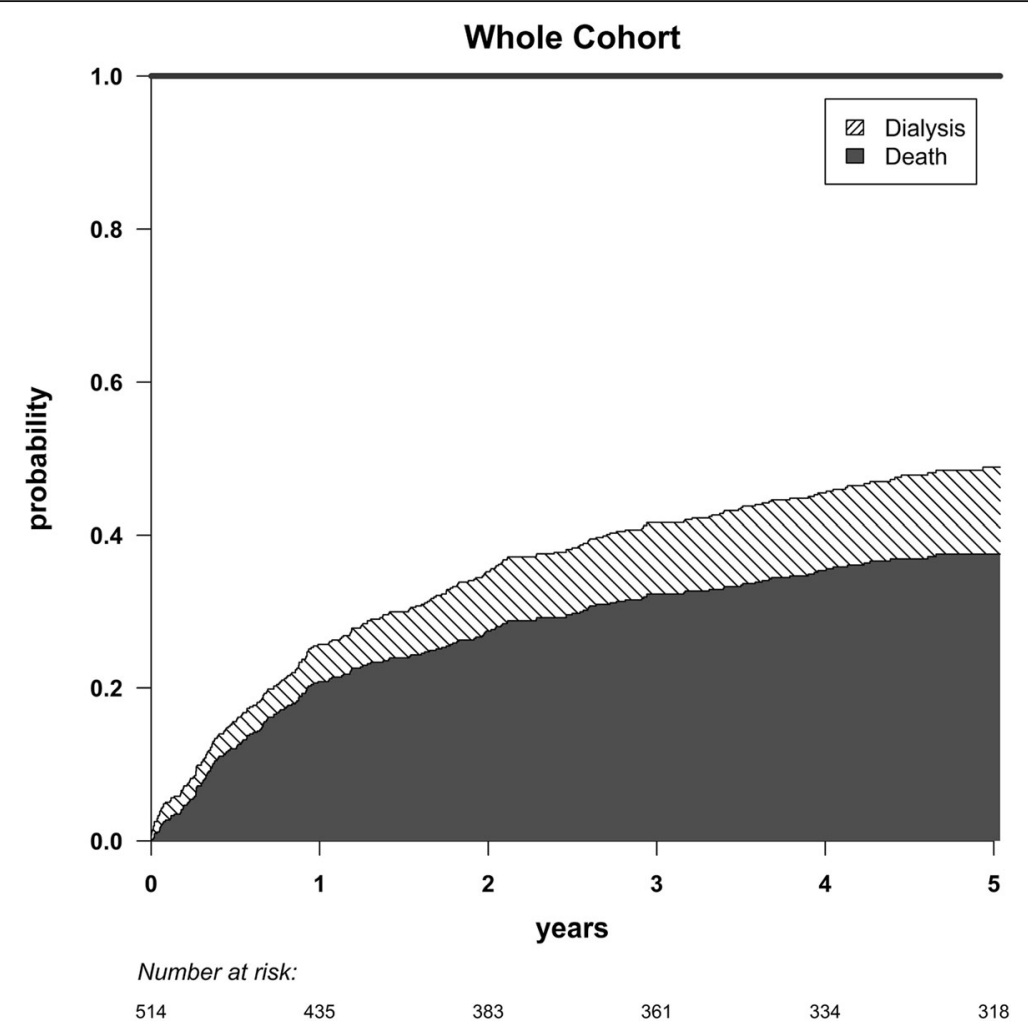

Fig. 3 Cumulative incidence of death and dialysis initiation during the follow-up. The cumulative incidence curves are stacked

implementation of longitudinal follow-up and the monitoring of CKD progression, and may therefore suggest prevention strategies.

One of the major strengths of our study is the innovative nature of the methodology based on repeated measurement of serum creatinine to confirm the persistence of renal injury. Firstly, it is worth noting that the systematic and automated self-reporting of abnormal creatinine levels above the cut-off value by laboratories may help primary care physicians detect more accurately patients at increased risk for CKD or in early stages, particularly among elderly [16, 22, 41, 42]. Secondly, asserting incidence and chronicity of the condition is of major interest to differentiate CKD from acute kidney injury (AKI) and not misclassify patients with an acute deterioration as chronic. Nearly $60 \%$ of patients with at least one increased value in creatinine level above $1.7 \mathrm{mg} / \mathrm{dL}$ had creatinine level under this cut-off value during the course of our study. All medical reports were appraised by an expert committee including nephrologists and epidemiologists. Study nurses systematically interviewed all clinical laboratories in order to track all measures under the cut-off value that would not have been reported. This work allowed us to assert the chronicity of renal disease. Thirdly, the large sample size and the prospective non interventional design with a longitudinal

Table 2 Progression of CKD according to the renal function during the study period $(N=503)$

\begin{tabular}{|c|c|c|c|c|}
\hline \multirow{2}{*}{$\begin{array}{l}\text { Annual progression of CKD } \\
N(\%)\end{array}$} & \multicolumn{4}{|c|}{ Patient's condition at the end of the study } \\
\hline & Without ESRD & ESRD & Death & Total \\
\hline Improvement of renal function $^{a}$ & $96(57.8 \%)$ & $12(7.2 \%)$ & $58(35 \%)$ & 166 \\
\hline Physiological decline $e^{b}$ & $74(69.8 \%)$ & $5(4.7 \%)$ & $27(25.5 \%)$ & 106 \\
\hline Moderate decline $e^{c}$ & $48(52.2 \%)$ & $12(13 \%)$ & $32(34.8 \%)$ & 92 \\
\hline Rapid decline ${ }^{d}$ & $39(28.1 \%)$ & $29(20.9 \%)$ & $71(51.0 \%)$ & 139 \\
\hline Total & 257 & 58 & 188 & 503 \\
\hline
\end{tabular}

CKD chronic kidney disease, ESRD end-stage renal disease

${ }^{a}$ if the difference between the final and initial values of serum creatinine ( $\mathrm{fSC}$-iSC) was $\leq 0$

$\mathrm{b}_{\text {if } 0} 0<\mathrm{fSC}-\mathrm{iSC} \leq 2$

if $2<\mathrm{fSC}-\mathrm{iSC}<5$

$\mathrm{d}_{\text {if }}$ fSC-iSC $\geq 5$ 
Table 3 Risk factors associated with death and dialysis initiation (univariable analyses)

\begin{tabular}{|c|c|c|c|c|c|c|c|c|}
\hline \multirow{3}{*}{ Variables } & \multicolumn{4}{|c|}{ Cox model } & \multicolumn{4}{|c|}{ Fine-Gray model } \\
\hline & \multicolumn{2}{|c|}{ Death } & \multicolumn{2}{|c|}{ Dialysis initiation } & \multicolumn{2}{|c|}{ Death } & \multicolumn{2}{|c|}{ Dialysis initiation } \\
\hline & $\mathrm{HR}$ & $95 \% \mathrm{Cl}$ & $\mathrm{HR}$ & $95 \% \mathrm{Cl}$ & $\mathrm{HR}$ & $95 \% \mathrm{Cl}$ & $\mathrm{HR}$ & $95 \% \mathrm{Cl}$ \\
\hline \multicolumn{9}{|l|}{ Age (years) } \\
\hline$<70$ & 1.00 & & 1.00 & & 1.00 & & 1.00 & \\
\hline $70-80$ & 1.91 & {$\left[\begin{array}{ll}1.23 & -2.97]\end{array}\right]$} & 0.44 & {$[0.23-0.84]$} & 2.07 & {$[1.34-3.22]$} & 0.39 & {$[0.21-0.75]$} \\
\hline $80-85$ & 1.87 & {$[1.15-3.03]$} & 0.30 & {$[0.13-0.74]$} & 2.06 & {$[1.28-3.33]$} & 0.27 & {$[0.11-0.66]$} \\
\hline$>85$ & 2.78 & {$[1.8-4.32]$} & 0.45 & {$[0.22-0.92]$} & 2.98 & {$\left[\begin{array}{lll}1.92 & -4.62\end{array}\right]$} & 0.36 & {$[0.17-0.73]$} \\
\hline \multicolumn{9}{|l|}{ Gender } \\
\hline Male & 1.00 & & 1.00 & & 1.00 & & 1.00 & \\
\hline Female & 1.13 & {$[0.84-1.52]$} & 1.37 & {$[0.81-2.32]$} & 1.10 & {$[0.82-1.49]$} & 1.27 & {$[0.75-2.15]$} \\
\hline \multicolumn{9}{|l|}{ Hemoglobin } \\
\hline$\geq 11 \mathrm{~g} / \mathrm{dL}$ & 1.00 & & 1.00 & & 1.00 & & 1.00 & \\
\hline$<11 \mathrm{~g} / \mathrm{dL}$ & 2.37 & {$[1.76-3.17]$} & 2.52 & {$[1.44-4.41]$} & 2.13 & {$[1.59-2.86]$} & 1.89 & {$[1.09-3.29]$} \\
\hline \multicolumn{9}{|l|}{ Cancer $<5$ years } \\
\hline No & 1.00 & & 1.00 & & 1.00 & & 1.00 & \\
\hline Yes & 1.67 & {$[1.18-2.35]$} & 0.95 & {$[0.45-2.01]$} & 1.62 & {$[1.14-2.32]$} & 0.78 & {$[0.37-1.67]$} \\
\hline \multicolumn{9}{|c|}{ Chronic heart failure } \\
\hline No & 1.00 & & 1.00 & & 1.00 & & 1.00 & \\
\hline Yes & 1.74 & {$[1.29-2.36]$} & 0.68 & {$[0.33-1.38]$} & 1.78 & {$[1.32-2.4]$} & 0.59 & {$[0.29-1.19]$} \\
\hline \multicolumn{9}{|c|}{ Ischemic cardiopathy } \\
\hline No & 1.00 & & 1.00 & & 1.00 & & 1.00 & \\
\hline Yes & 1.28 & {$[0.95-1.72]$} & 0.80 & {$[0.44-1.43]$} & 1.30 & {$[0.97-1.74]$} & 0.75 & {$[0.42-1.34]$} \\
\hline \multicolumn{9}{|l|}{ Stroke } \\
\hline No & 1.00 & & 1.00 & & 1.00 & & 1.00 & \\
\hline Yes & 1.45 & {$[0.94-2.25]$} & 0.57 & {$[0.18-1.84]$} & 1.48 & {$[0.96-2.3]$} & 0.52 & {$[0.16-1.68]$} \\
\hline \multicolumn{9}{|c|}{ Peripheral arterial disease } \\
\hline No & 1.00 & & 1.00 & & 1.00 & & 1.00 & \\
\hline Yes & 1.07 & {$[0.76-1.52]$} & 1.55 & {$[0.87-2.75]$} & 1.03 & {$[0.73-1.44]$} & 1.59 & {$[0.9-2.81]$} \\
\hline \multicolumn{9}{|l|}{ Diabetes } \\
\hline No & 1.00 & & 1.00 & & 1.00 & & 1.00 & \\
\hline Yes & 0.92 & {$[0.68-1.25]$} & 2.54 & {$\left[\begin{array}{lll}1.51 & -4.28\end{array}\right]$} & 0.88 & {$[0.65-1.18]$} & 2.62 & {$[1.56-4.41]$} \\
\hline \multicolumn{9}{|c|}{ High blood pressure } \\
\hline No & 1.00 & & 1.00 & & 1.00 & & 1.00 & \\
\hline Yes & 0.82 & {$[0.6-1.11]$} & 0.85 & {$[0.48-1.5]$} & 0.85 & {$[0.62-1.15]$} & 0.90 & {$\left[\begin{array}{lll}0.51 & -1.58\end{array}\right]$} \\
\hline \multicolumn{9}{|l|}{ Others } \\
\hline No & 1.00 & & 1.00 & & 1.00 & & 1.00 & \\
\hline Yes & 1.56 & {$[0.96-2.53]$} & 1.18 & {$[0.54-2.61]$} & 1.54 & {$[0.94-2.52]$} & 1.08 & {$[0.49-2.39]$} \\
\hline \multicolumn{9}{|l|}{ eGFR } \\
\hline$>20 \mathrm{~mL} / \mathrm{min}$ & 1.00 & & 1.00 & & 1.00 & & 1.00 & \\
\hline$<20 \mathrm{~mL} / \mathrm{min}$ & 1.30 & {$[0.77-2.2]$} & 6.93 & [3.96 -12.13] & 0.85 & {$[0.49-1.48]$} & 6.04 & {$[3.39-10.74]$} \\
\hline
\end{tabular}

$X$ variables entered into the multivariable analyses

$\mathrm{Cl}$ confidence interval, eGFR estimated glomerular filtration rate using MDRD formula (Modification of the Diet in Renal Disease), HR hazard ratio

follow-up add to the robustness of our findings reflecting real life. Finally, competing risks analyses showed that most patients died prior to the stage of ESRD and allowed us to identify predictive factors associated to death and dialysis initiation. Age at diagnosis, presence of anemia, CHF and active neoplasia were independent 
Table 4 Risk factors associated with death and dialysis initiation (multivariable analyses). Covariates were selected in the multivariable analysis using a stepwise procedure adapted to multiple imputation methodology

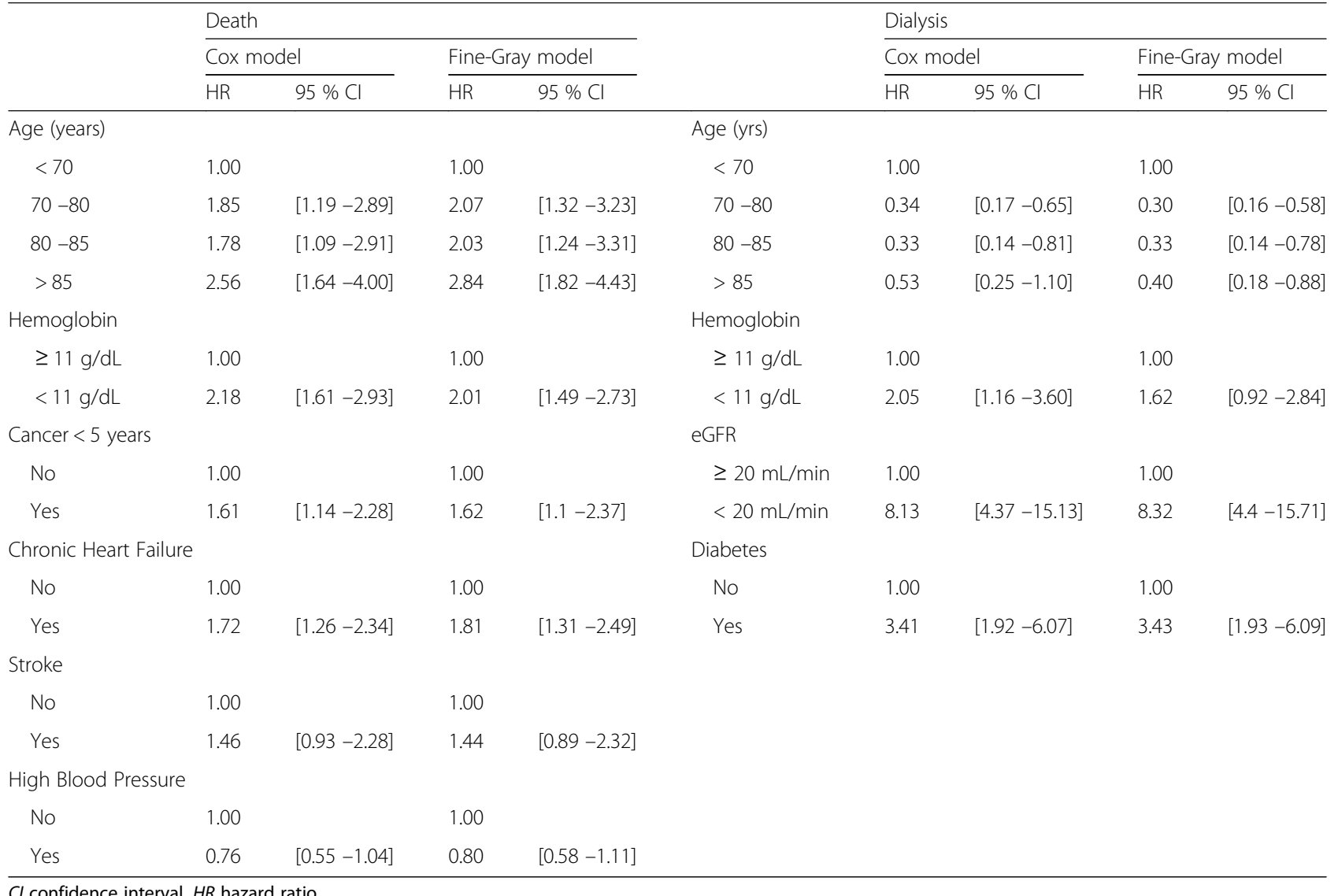

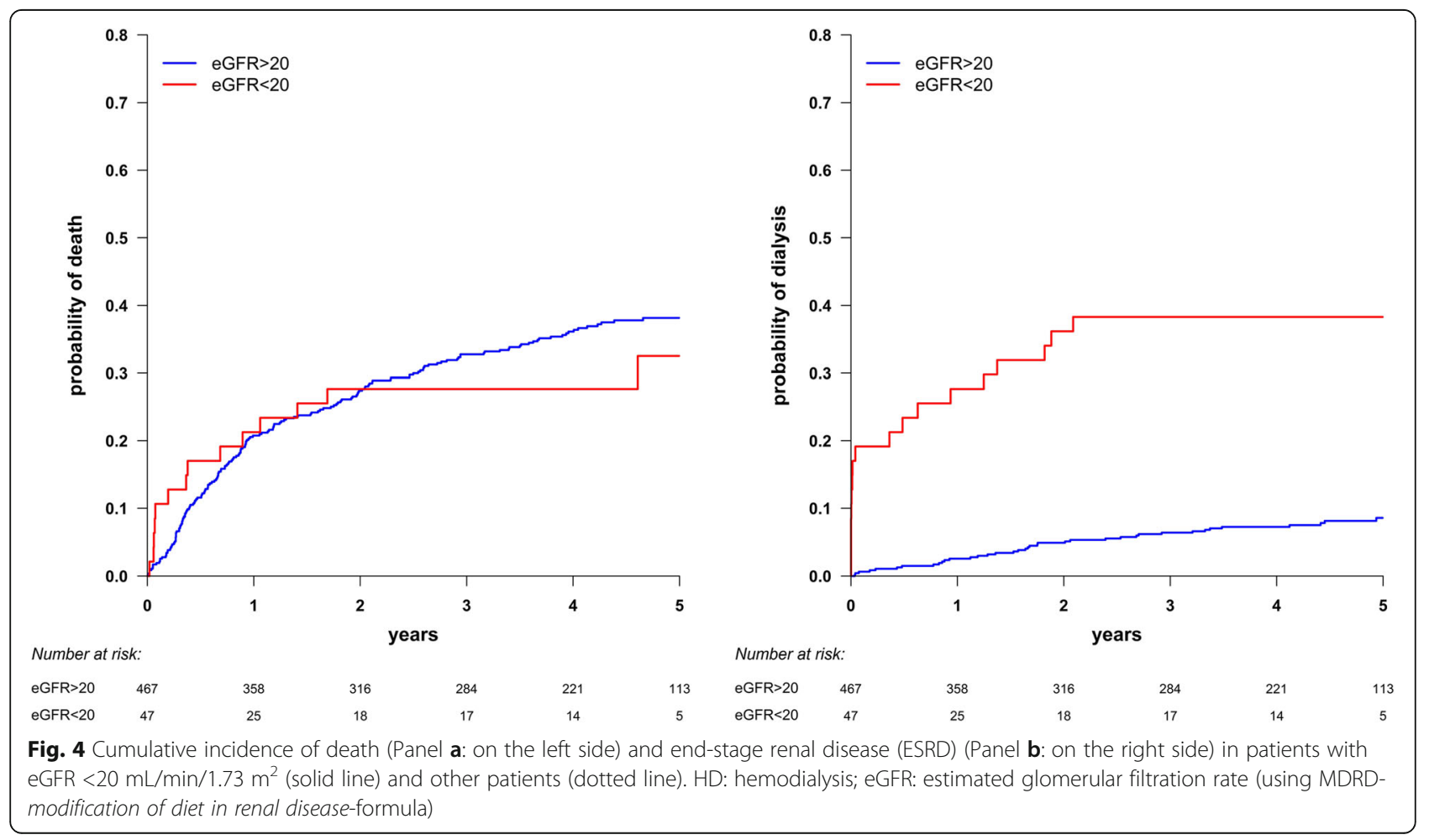


risk factors for all-cause mortality. Our results are consistent with those previously reported [7]. Anemia develops as a frequent complication of CKD, and can have a deleterious effect not only on progression of CKD but also on progression of cardiovascular diseases and events [1]. In our study, $45.9 \%$ of incident CKD patients (stages 3 to 5) experienced decline of their renal function during the course of the study, and those with a fast decline were more likely to reach ESRD or death, as previously shown among prevalent CKD patients [10, 43]. In addition, eGFR was not associated with risk of death that was inconsistent with previous findings [10,44]. Go et al found non linear relations between the GFR and the risk of death [10]. In 38,520 non-dialysis-dependent CKD patients, each $5 \mathrm{~mL} / \mathrm{min} / 1.73 \mathrm{~m}^{2}$ decline in eGFR was associated with higher risk of death due to cardiovascular disease (hazard ratio: 1.10; 95 \% confidence interval: 1.08 to 1.12) [44]. The first possible explanation for our contradictory results is the selection of incident patients whereas those previous studies included prevalent patients. All the published data that correlated eGFR with death were observed in studies performed in prevalent CKD patients. Prevalent CKD patients are different from incident CKD patients because of a survival bias due to the non-inclusion of patients who have died before the study starts and to the fact that development of CKD increases the risk of death. A second explanation is supported by clinical characteristics of patients included in the EPIRAN study; they were mostly stage 3 CKD patients at the time of diagnosis and non progressors $(54.1 \%)$. From our point of view, progression of CKD played a major role when it was found to be associated with risk of death in prevalent patients. Finally, a completely different explanation could be supported by recent findings. Mandelli et al. assessed mortality prediction in the oldest old (aged 85 years and older) with five different equations to estimate GFR They showed that risk of mortality was significantly higher for reduced GFR estimated with the Berlin Initiative Study-1 and Cockroft-Gault equations over the short time, whereas the MDRD formula appeared a more consistent predictor after five years [45]. However, a significantly higher risk of death after 5 years was found in the oldest old with a very low eGFR $\left(<30 \mathrm{~mL} / \mathrm{min} / 1.73 \mathrm{~m}^{2}\right)$, irrespective of the equation. In addition, we found that independent risk factors significantly associated with dialysis initiation were age at diagnosis, presence of diabetes and GFR below $20 \mathrm{~mL} / \mathrm{min} / 1.73 \mathrm{~m}^{2}$. Interestingly, elderly (>70 years) were less likely to undergo dialysis. This may be due to a bias towards nephrology referral and indication for dialysis, a low likelihood of experiencing progression of CKD to ESRD in elderly or a patient choice [46].
CKD patients identified in our cohort were mainly stages 3-4 primary care patients, but the first abnormal creatinine level (above the cut-off value) was measured in a public or private hospital for $42.8 \%$ of patients. For serum creatinine measurements ordered by a non nephrologist specialist, they were done mostly within a standard medical checkup that was not systematically transmitted to the family GP, and as a result, delayed CKD diagnosis. Clinical inertia in response to CKD diagnosis was seen in primary care but also with specialist care, whether they worked in healthcare institutions or not. The same phenomenon was observed for the check up to diagnose CKD. Proteinuria was sought only in $7.9 \%$ of patients despite French recommendations for diagnosis and management of CKD and international guidelines advocating systematic screening for markers of kidney damage such as proteinuria [47-50]. Proteinuria is predictive for CKD progression but also for progression to ESRD [5, 48, 51-55]. Proteinuria was also shown to impact on the occurrence of cardiovascular events [56]. Reduction of proteinuria is therefore a major determinant for reducing the risk of CKD progression to ESRD and cardiovascular events [49, 57-61]. Our study confirm that early identification of CKD patients on the basis of presence of reduced eGFR or proteinuria is desirable to permit early intervention for reducing risk of cardiovascular events, progression to kidney failure or death [62]. Over the past decade, the therapeutic arsenal to reduce CKD burden, such as prevention of complications, slowing progression, and prevention of cardiovascular risk, has markedly expanded $[48,50,63]$. However, practice patterns suggest that physicians remain unfamiliar with recommendations for detection and management of CKD as highlighted in several studies [64-67]. The lack of acute awareness of clinical practice guidelines for CKD varies according to the type of registration status (nephrologist $>$ specialist $>$ GP) $[65,66]$. As early detection is within the realm of the family GPs, they should feel more comfortable with making the initial diagnosis of CKD and providing appropriate primary and ongoing care to patients.

Regarding medical monitoring of patients, our findings demonstrated that only $28.3 \%$ of patients were referred to a nephrologist after CKD diagnosis. There is probably a bias in nephrologist referral related to the age of patients. It is indeed possible that GPs chose not to refer elderly to nephrologists because 1) they felt that elderly could not be candidates for RRT, and 2) reduced GFR remained relatively stable in most of them. Several recent studies showed the benefit of conservative management in elderly as long as they remained asymptomatic [68]. A prospective, community-based study provided a compelling evidence for a causal relationship between pre-ESRD medical care and outcomes [69]. 
A recent literature review focusing on studies regarding changes in kidney function over time highlighted the importance of incorporating the rate of kidney decline in the staging of CKD for better risk stratification on mortality and cardiovascular outcomes for individual patients as CKD is a dynamic [70]. Although most CKD patients will die from cardiovascular disease rather than progress to kidney failure, it is of interest to develop prevention programs for patients who will progress to ESRD, such as tertiary preventive care and regular monitoring to detect early patients most likely to progress. This will let appropriate referral of patients who might benefit from a nephrology service while allowing the majority to remain in primary care, and prevent that local nephrology services become overwhelmed [71]. Nevertheless, it is mandatory to conduct medical surveillance in those remaining in primary care, and avoid all situations (iatrogenic and not) which may lead to worsening of renal function or decompensate.

The following limitations should be considered. First, we used a single creatinine cut-off value as inclusion criterion to define impaired renal function because French clinical laboratories did not calculate eGFR when we designed the study. Although French clinical laboratories were required to report eGFR for each creatinine value in 2005 , we could not change this main inclusion criterion during the study. The creatinine cut-off value of $1.7 \mathrm{mg} / \mathrm{dL}$ was selected on the basis of the only published incidence study when the EPIRAN study was designed [40]. Drey et al. used this value as recommended by the Renal Association [72]. CKD diagnosis could only be assigned to patients who had had serum creatinine measurement, and more specifically those who had repeated measurement. As a result, incidence of CKD may be underestimated, because only patients with serum creatinine repeated measurement were included in our study. However, this cut-off value allowed to detect a majority of new patients having stage 3 CKD and avoid misclassification of healthy elderly people with eGFR $<60 \mathrm{~mL} / \mathrm{min}$. Second, because of the non interventional design of our study, only patients who were prescribed creatinine measurement could be identified. Another limitation was the scarcity of proteinuria determination, although presence of proteinuria was recognized to predispose to ESRD, even with a normal renal function $[3,5,13,55,57,59,60]$. Our results were consistent with previous findings highlighting that special attention must be paid to improve albuminuria screening $[3,5]$. Despite these limitations, a non interventional approach is the only possible way of studying management of patients in real life.

\section{Conclusion}

In conclusion, our study provided annual incidence rate of CKD stage 3 to 5 in a community-based population, confirmed that death was far more likely than advancement to RRT in CKD patients, identified predictors of death and dialysis initiation, and highlighted the need to improve the hands-on implementation of guidelines for the evaluation and management of CKD in primary care.

\begin{abstract}
Abbreviations
AKI: Acute kidney injury; BMI: Body mass index; CHF: Congestive heart failure; Cl: Confidence interval; CKD: Chronic kidney disease; DBP: Diastolic blood pressure; eGFR: Estimated glomerular filtration rate; ESRD: End-stage renal disease; GP: General physician; Hb: Hemoglobin; HR: Hazard ratio; Max: Maximum; MDRD formula: Simplified modification of the diet in renal disease; Min: Minimum; pmp: Per million population; Q1: Quartile 1;

Q2: Quartile 2; REIN registry: French Renal Epidemiology and Information Network registry; RRT: Renal replacement therapy; SBP: Systolic blood pressure; SCf-SCi: Difference between the initial and final values of serum creatinine; STD: Standard deviation; UCGN: Urban Community of Greater Nancy
\end{abstract}

\section{Acknowledgements}

Responsibility for the design, analysis, interpretation of data and conclusion lies with the authors. All authors gave their final approval regarding submission for publication. All authors read and approved the final manuscript.

The authors are extremely grateful to all the clinical laboratories and Clinical Research associates involved in this study for their kind cooperation, and for providing high quality data. They would like to especially thank Catherine Litscher for data management and clinical monitoring and Brigitte Bourdillat for the manuscript editing.

\section{Funding}

This study was supported by a public funding through a Hospital Clinical Research Program (PHRC 2002).

\section{Availability of data and materials}

The datasets during and/or analyzed during the current study are available from the corresponding author on reasonable request.

\section{Authors 'contributions}

MK conceived the idea of the study. MK and SB designed the study, were responsible of data collection, critically reviewed and validated all exclusions and inclusions, and confirmed the persistence of renal injury for all included patients, using a standardized process. MK, SB, CA, JBB, AD were responsible of undertaking data analysis and contributed to the interpretation of the results. CA produced the tables and graphs. The first draft of the manuscript was prepared by $C A$ and was then circulated repeatedly among all authors for critical revision. CA, JBB, SB, AD, LF, and MK gave their final approval regarding submission for publication. $C A, J B B, S B, A D, L F$, and $M K$ read and approved the final manuscript.

\section{Competing interests}

The authors declare that they have no competing interests.

\section{Consent for publication}

Not applicable.

\section{Ethics approval and consent to participate}

Approvals from the National Advisory Committee on information processing research in the field of health (CCTIRS) and from the National Commission on Informatics and Liberties (CNIL) were obtained (CCTIRS Nº2 147 and CNIL N 902222).

Each participating laboratory was given collective information. Each patient was given written information describing data collection from medical records. Collective information was also displayed in doctors' offices and laboratories. A patient consent was not required as the design of the EPIRAN study was observational. However, each patient could exercise his/her rights to oppose the use of his/her medical data for the study by letter. 
Data concerning patients were collected in a strictly non identifying manner. An anonymity code was assigned to each patient to prevent linkage between personal data and medical data.

\section{Author details}

${ }^{1}$ INSERM, CIC-EC 1433, Nancy, France. ${ }^{2}$ Pôle S2R, Epidemiology and clinical evaluation, University Hospital, Vandoeuvre-les-Nancy, France. ${ }^{3}$ Geriatric Department, University Hospital, Lille, France. ${ }^{4}$ Department of Biostatistics, UDSL, Lille EA2694, France. ${ }^{5}$ Lorraine University, Paris Descartes University, Apemac, Nancy EA4360, France. ${ }^{6}$ Department of Nephrology, University Hospital, Vandœuvre-les-Nancy, France.

Received: 1 August 2016 Accepted: 26 October 2016 Published online: 15 November 2016

\section{References}

1. Levey AS, Coresh J. Chronic kidney disease. Lancet. 2012;379:165-80

2. McCullough K, Sharma P, Ali T, Khan I, Smith W, MacLeod A, et al. Measuring the population burden of chronic kidney disease: a systematic literature review of the estimated prevalence of impaired kidney function. Nephrol Dial Transplant. 2012;27:1812-21.

3. Assogba GFA, Couchoud C, Roudier C, Pornet C, Fosse S, Romon I, et al. Prevalence, screening and treatment of chronic kidney disease in people with type 2 diabetes in France: the ENTRED surveys (2001 and 2007). Diabetes Met. 2012;38:558-66.

4. Zhang Q, Rothenbacher D. Prevalence of chronic kidney disease in population-based studies: systematic review. BMC Public Health. 2008;8:117.

5. Lameire N, Jager K, Van Biesen W, de Bacquer D, Vanholder R. Chronic kidney disease: a European perspective. Kidney Int. 2005;68:S30-8.

6. Bowling CB, Booth JN, Gutiérrez OM, Kurella Tamura M, Huang L, Kilgore M, et al. Non disease-specific problems and all-cause mortality among older adults with CKD: The REGARDS Study. Clin J Am Soc Nephrol. 2014;9:1737-45.

7. Keith DS, Nichols GA, Gullion CM, Betz Brown J, Smith D. Longitudinal follow-up and outcomes among a population with chronic kidney disease in a large managed care organization. Arch Intern Med. 2004;164:659-63.

8. Foley RN, Murray AM, Li S, Herzog CA, McBean AM, Eggers PW, et al. Chronic kidney disease and the risk for cardiovascular disease, renal replacement, and death in the United states Medicare population, 1998 to 1999. J Am Soc Nephrol. 2005;16:489-95.

9. Vanholder R, Massy Z, Argiles A, Spasovski G, Verbeke F, Lameire N. for the European Uremic Toxin Work Group (EUTox). Chronic kidney disease as cause of cardiovascular morbidity and mortality. Nephrol Dial Transplant. 2005;20:1048-56.

10. As G, Chertow GM, Fan D, McCulloch CE, Hsu CY. Chronic kidney disease and the risks of death, cardiovascular events, and hospitalization. N Engl J Med. 2004;351:1296-305.

11. Collins AJ, Li S, Gilbertson DT, Liu J, Chen SC, Herzog CA. Chronic kidney disease and cardiovascular disease in the Medicare population. Kidney Int 2003;87:S24-31.

12. O'Hare AM, Choi Al, Bertenthal D, Bacchetti P, Garg AX, Kaufman JS, et al. Age affects outcomes in chronic kidney disease. J Am Soc Nephrol. 2007;18: 2758-65.

13. Jones $C$, Roderick $P$, Harris $S$, Rogerson M. Decline in kidney function before and after nephrology referral and the effect on survival in moderate to advanced chronic kidney disease. Nephrol Dial Transplant. 2006;21:2133-43.

14. Roderick PJ, Atkins RJ, Smeeth L, Nitsch DM, Hubbard RB, Flectchter AE, et al. Detecting chronic kidney disease in older people; what are the implications? Age Ageing. 2008;37:179-86.

15. Hemmelgarn BR, Zhang J, Manns BJ, James MT, Quinn RR, Ravani P, et al. for the Alberta Kidney Disease Network. Nephrology visits and health care resource use before and after reporting estimated glomerular filtration rate. JAMA. 2010;303:1151-58

16. Hallan SI, Dahl K, Oien CM, Grootendorst DC, Aasberg A, Holmen J, et al. Screening strategies for chronic kidney disease in the general population: follow-up of cross sectional health survey. BMJ. 2006;333:1047.

17. Innes A. The detection of advanced chronic kidney disease by surveillance of elevated plasma creatinines - a five-year experience. Nephrol Dial Transplant. 2008;23:2571-75.

18. Akbary A, Swedko PJ, Clark HD, Hogg W, Lemelin J, Magner P, et al. Detection of chronic kidney disease with laboratory reporting of estimated glomerular filtration rate and an educational program. Arch Intern Med. 2004;164:1788-92.

19. Richards N, Harris K, Whitfield M, O'Donoghue D, Lewis R, Mansell M, et al. The impact of population-based identification of chronic kidney disease using estimated glomerular filtration rate (eGFR) reporting. Nephrol Dial Transplant. 2008;23:556-61.

20. Bello AK, Peters J, Wight J, de Zeeuw D, El Nahas M, on behalf of the European Kidney Institute. A population-based screening for microalbuminuria among relatives of CKD patients: the Kidney Evaluation and Awareness Program in Sheffield (KEAPS). Am J Kidney Dis. 2008;52:434-43.

21. Grootendorst DC, Jager KJ, Zoccali C, Dekker FW. Screening: why, when, and how. Kidney Int. 2009;76:694-9.

22. Rayner HC, Baharani J, Dasgupta I, Suresh V, Temple RM, Thomas ME, et al. Does community-wide chronic kidney disease management improve patient outcomes? Nephrol Dial Transplant. 2014;29:644-9.

23. Minutolo R, Lapi F, Chiodini P, Simonetti M, Bianchini E, Pecchioli S, et al. Risk of ESRD and death in patients with CKD not referred to a nephrologist: a 7-year prospective study. Clin J Am Soc Nephrol. 2014;9:1586-93.

24. Levey AS, Coresh J, Greene T, Stevens LA, Zhang YL, Hendriksen S, et al. Chronic Kidney Disease Epidemiology Collaboration. Using standardized serum creatinine values in the modification of diet in renal disease study equation for estimating glomerular filtration rate. Ann Intern Med. 2006;145: 247-54.

25. KDOQI clinical practice guidelines for chronic kidney disease evaluation, classification, and stratification. Kidney Disease Outcomes Quality Initiative. Am J Kidney Dis. 2002;39:S1-266.

26. Couchoud C, Stengel B, Landais P, Aldigier JC, de Cornelissen F, Dabot C, et al. The renal epidemiology and information network (REIN): a new registry for end-stage renal disease in France. Nephrol Dial Transplant. 2006;21:411-8.

27. Registre décès Inserm, Centre d'épidémiologie des décès-Cepidc, http:// www.cepidc.inserm.fr. Accessed 29 Oct 2016.

28. Recensement INSEE. 1999. 2006. http://www.insee.fr/fr/bases-de-donnees/ default.asp?page=historique-resultats-statistiques.htm. Accessed 29 Oct 2016.

29. European health for all database 2014 (HFA-DB) WHO regional office for Europe updated April 2014, http://data.euro.who.int/hfadb/. Accessed 29 Oct 2016.

30. Kalbfleisch JD, Prentice RL. Competing risks and multistate models. In: Balding DJ, editor. The statistical analysis of failure time data, Series in probability and statistics, vol. Chap 8. Secondth ed. New York: Wiley Interscience; 2002. p. 247-77.

31. Prentice RL, Kalbfleisch JD, Peterson AVJ, Flournoy N, Farewell VT, Breslow $\mathrm{NE}$. The analysis of failure times in the presence of competing risks. Biometrics. 1978;34:541-54.

32. Putter H, Fiocco M, Geskus RB. Tutorial in biostatistics: competing risks and multi-state models. Stat Med. 2007;26:2389-430.

33. Latouche A, Allignol A, Beyersmann J, Labopin M, Fine JP. A competing risks analysis should report results on all cause-specific hazards and cumulative incidence functions. J Clin Epidemiol. 2013;66:648-53.

34. Van Buuren S, Groothuis-Oudshoorn K. MICE: Multivariate Imputation by Chained Equations in R. J Stat Softw. 2011;45:1-67.

35. Marshall A, Altman D, Holder R. Comparison of imputation methods for handling missing covariate data when fitting a Cox proportional hazards model: a resampling study. BMC Med Res Methodol. 2010;10:112.

36. Wood AM, White IR, Royston P. How should variable selection be performed with multiply imputed data? Stat Med. 2008;27:3227-46.

37. Rubin DB. Multiple imputation after 18+ years. J Am Stat Assoc. 1996;91:473-89.

38. Therneau T, Gramsch P, Fleming T. Martingale-based residuals for survival models. Biometrika. 1990;77:147-60.

39. R Foundation for Statistical Computing. R Development Core Team (2010): R: A Language and Environment for Statistical Computing. Vienna, Austria: http://www.R-project.org. Accessed 29 Oct 2016.

40. Drey N, Roderick P, Mullee M, Rogerson M. A population-based study of the incidence and outcomes of diagnosed chronic kidney disease. Am J Kidney Dis. 2003:42:677-84.

41. Rule AD, Rodeheffer RJ, Larson TS, Burnett JC, Cosio FG, Turner ST, et al. Limitations of estimating glomerular filtration rate from serum creatinine in the general population. Mayo Clin Proc. 2006;81:1427-34.

42. Richards N, Harris K, Whitfield M, O'Donoghue D, Lewis R, Mansell M, et al. Primary care-based disease management of chronic kidney disease (CKD), based on estimated glomerular filtration rate (eGFR) reporting, improves patient outcomes. Nephrol Dial Transplant. 2008;23:549-55. 
43. Xie Y, Bowe B, Xian H, Balasubramanian S, Al-Aly Z, et al. Estimated GFR trajectories of people entering CKD stage 4 and subsequent kidney disease outcomes and mortality. Am J Kidney Dis. 2016 [Epub ahead of print].

44. Navaneethan SD, Schold JD, Arrigain S, Jolly SE, Nally Jr JV. Cause-specific deaths in non-dialysis-dependent CKD. J Am Soc Nephrol. 2015;26:2512-20.

45. Mandelli S, Riva E, Tettamanti M, Detoma P, Giacomin A, Lucca U. Mortality prediction in the oldest old with five different equations to estimate glomerular filtration rate : the health and anemia population-based study. PLoS One. 2015. doi:10.1371/journal.pone.0136039.

46. Faller B, Beuscart JB, Frimat L. Association des néphrologues de l'Est. Competingrisk analysis of death and dialysis initiation among elderly ( $\geq 80$ years) newly referred to nephrologists: a French prospective study. BMC Nephrol. 2013;14:103.

47. ANAES : Diagnostic de l'insuffisance rénale chronique chez l'adulte. Recommandations. 2002. http://www.has-sante.fr/portail/upload/docs/ application/pdf/irc_chez_ladulte_2002_-_synth_350se.pdf. Accessed 29 Oct 2016.

48. ANAES : Moyens thérapeutiques pour ralentir la progression de l'insuffisance rénale chronique chez l'adulte. 2006. http://www.has-sante.fr/portail/upload/ docs/application/pdf/IRC_2006_recos.pdf. Accessed 29 Oct 2016.

49. Crowe E, Halpin D, Stevens $P$, on behalf of the Guideline Development Group. Early identification and management of chronic kidney disease: summary of NICE guidance. BMJ. 2008;337:a1530.

50. National Kidney Foundation. K/DOQI clinical practice guidelines for chronic kidney disease: evaluation, classification, and stratification. Am J Kidney Dis. 2002;39:S1-266.

51. Verhave JC, Gansevoort RT, Hillege HL, Bakker SJ, de Zeeuw D, de Jong PE, PREVEND Study Group. An elevated urinary albumin excretion predicts de novo development of renal function impairment in the general population. Kidney Int Suppl. 2004;92:S18-21.

52. Peterson JC, Adler S, Burkart JM, Greene T, Hebert LA, Hunsicker LG, et al. Blood pressure control, proteinuria, and the progression of renal disease. The Modification of Diet in Renal Disease Study. Ann Intern Med. 1995;123:754-62.

53. Keane WF, Zhang Z, Lyle PA, Cooper ME, de Zeeuw D, Grunfeld JP, et al. RENAAL Study Investigators. Risk scores for predicting outcomes in patients with type 2 diabetes and nephropathy: the RENAAL study. Clin J Am Soc Nephrol. 2006;1:761-7.

54. Iseki K, Uehara H, Nishime K, Tokuyama K, Yoshihara K, Kinjo K, et al. Impact of the initial levels of laboratory variables on survival in chronic dialysis patients. Am J Kidney Dis. 1996;28:541-8.

55. Iseki K, Kinjo K, Iseki C, Takishita S. Relationship between predicted creatinine clearance and proteinuria and the risk of developing ESRD in Okinawa, Japan. Am J Kidney Dis. 2004;44:806-14.

56. Gerstein HC, Mann JF, Yi Q, Zinman B, Dinneen SF, Hoogwerf B, et al. HOPE Study Investigators. Albuminuria and risk of cardiovascular events, death, and heart failure in diabetic and nondiabetic individuals. JAMA. 2001;286:421-6.

57. Atkins RC, Briganti EM, Lewis JB, Hunsicker LG, Braden G, de Crespigny PJ C, et al. Proteinuria reduction and progression to renal failure in patients with type 2 diabetes mellitus and overt nephropathy. Am J Kidney Dis. 2005;45:281-7.

58. Jafar TH, Stark PC, Schmid CH, Landa M, Maschio G, Marcantoni C, AIPRD Study Group, et al. Proteinuria as a modifiable risk factor for the progression of non-diabetic renal disease. Kidney Int. 2001;60:1131-40.

59. Ruggenenti P, Perna A, Remuzzi G, GISEN Group Investigators. Retarding progression of chronic renal disease: the neglected issue of residual proteinuria. Kidney Int. 2003;63:2254-61.

60. Araki S, Haneda M, Koya D, Hidaka H, Sugimoto T, Isono M, et al. Reduction in microalbuminuria as an integrated indicator for renal and cardiovascular risk reduction in patients with type 2 diabetes. Diabetes. 2007;56:1727-30.

61. Kent DM, Jafar TH, Hayward RA, Tighiouart H, Landa M, de Jong P, et al. Progression risk, urinary protein excretion, and treatment effects of angiotensin-converting enzyme inhibitors in nondiabetic kidney disease. J Am Soc Nephrol. 2007;18:1959-65.

62. James MT, Hemmelgarn BR, Tonelli M. Early recognition and prevention of chronic kidney disease. Lancet. 2010;375:1296-309.

63. HAS: Moyens thérapeutiques pour ralentir la progression de l'insuffisance rénale chronique chez l'adulte. 2004. http://www.has-sante.fr/portail/jcms/c 272372/fr/moyens-therapeutiques-pour-ralentirlaprogression-delinsuffisance-renale-chronique-chez-ladulte. Accessed 29 Oct 2016.

64. Agrawal V, Ghosh AK, Barnes MA, McCullough PA. Perception of indications for nephrology referral among internal medicine residents: a national online survey. Clin J Am Soc Nephrol. 2009:4:323-8.
65. Charles RF, Powe NR, Jaar BG, Troll MU, Parekh RS, Boulware LE. Clinical testing patterns and cost implications of variation in the evaluation of CKD among US physicians. Am J Kidney Dis. 2009;54:227-37.

66. Wasse $\mathrm{H}, \mathrm{McClellan}$ WM. Increasing physician knowledge about the diagnosis and management of CKD: how can we help primary care providers? Am J Kidney Dis. 2009;54:187-90.

67. Stevens LA, Fares G, Fleming J, Martin D, Murthy K, Qiu J, et al. Low rates of testing and diagnostic codes usage in a commercial clinical laboratory: evidence for lack of physician awareness of chronic kidney disease. J Am Soc Nephrol. 2005;16:2439-48.

68. Cooper BA, Branley P, Bulfone L, Collins JF, Craig JC, Fraenkel MB, et al. IDEAL Study: A randomized, controlled trial of early versus late initiation of dialysis. N Engl J Med. 2010;363:609-19.

69. Kessler M, Frimat L, Panescu V, Briançon S. Impact of nephrology referral on early and midterm outcomes in ESRD: EPidémiologie de I'Insuffisance REnale chronique terminale en Lorraine (EPIREL): results of a 2-year, prospective, community-based study. Am J Kidney Dis. 2003;42:474-85.

70. Sohel BM, Rumana N, Ohsawa M. Turin TC. Kelly MA: Al Mamun M. Renal function trajectory over time and adverse clinical outcomes. Clin Exp Nephrol; 2016 [Epub ehead of print].

71. Glassock RJ. Referrals for chronic kidney disease. Real problem or nuisance? JAMA. 2010;303:1201-3.

72. The Renal Association. Treatment of adult patients with renal failure. Recommended standards and audit measures. Second edition 1997. http:// www.renal.org/docs/default-source/guidelines-resources/Renal_Association_ Standards_2nd_Edition_1997-2002.pdf?sfvrsn=0. Accessed 29 Oct 2016.

\section{Submit your next manuscript to BioMed Central and we will help you at every step:}

- We accept pre-submission inquiries

- Our selector tool helps you to find the most relevant journal

- We provide round the clock customer support

- Convenient online submission

- Thorough peer review

- Inclusion in PubMed and all major indexing services

- Maximum visibility for your research

Submit your manuscript at www.biomedcentral.com/submit
) Biomed Central 